\title{
On a Logical Argument Against the Naturalizability of Reference*
}

\author{
Andrea BIANCHI
}

Received: 01/08/2016

Final Version: 27/02/2017

BIBLID 0495-4548(2017)32:2p.145-160

DOI: $10.1387 /$ theoria. 16803

ABSTRACT: Is a naturalistic account of reference possible? Here is a simple argument to the effect that it is not: Let $\mathrm{R}$ be the relation that allegedly naturalizes reference, and consider the predicate "being an object that does not stand in the relation R to this expression". Call this predicate "P". On the face of it, P is a counterexample to the alleged naturalization, since it appears to refer to all and only those objects that do not stand in the relation $\mathrm{R}$ to it. Actually, an argument like this was advanced more than twenty years ago by the late Paolo Casalegno. Although for various reasons it has not been given due attention by the philosophical community, the argument is interesting in its structure and remarkable in its conclusion. In this paper I shall reconstruct it in detail and discuss it. Then, I shall show that the argument fails, since, contrary to what Casalegno claimed, under certain conditions $P$ is paradoxi$\mathrm{cal}$, hence not a referring expression. My rejection builds on the fundamental distinction between simple and compound expressions, namely on the compositional structure of natural languages. If I am right, whether any attempt at naturalizing reference that takes care of this distinction will succeed remains an open empirical question.

Keywords: reference, naturalization, semantic paradoxes, compositionality.

RESUMEN: ¿Es posible dar una explicación naturalista de la referencia? Lo que sigue es un argumento sencillo que muestra que no lo es: sea $\mathrm{R}$ la relación que, supuestamente, naturaliza la referencia, y considérese el predicado «ser un objeto que no satisface la relación $\mathrm{R}$ con esta expresión». Llámese «P» a este predicado. A la vista de ello, $\mathrm{P}$ es un contraejemplo a esa supuesta naturalización, puesto que parece referir a todos y sólo a aquellos objetos que no satisfacen la relación $\mathrm{R}$ con él. De hecho, un argumento semejante fue propuesto hace más de veinte años por Paolo Casalegno, ya fallecido. Si bien, por diferentes razones, no ha recibido la debida atención por parte de la comunidad filosófica, el argumento tiene una estructura interesante y una conclusión destacable. En este artículo voy a reconstruirlo en detalle y a discutirlo. A continuación mostraré que el argumento es fallido, pues, en contra de lo defendido por Casalegno, bajo determinadas condiciones $\mathrm{P}$ es paradójico y, por tanto, no es una expresión referencial. Mi rechazo se apoya en una distinción fundamental entre expresiones simples y compuestas, en concreto en la estructura composicional de las lenguas naturales. Si tengo razón, la cuestión de si algún intento de naturalizar la referencia que tenga en cuenta esta distinción podría tener éxito permanece como una cuestión empírica abierta.

Palabras clave: referencia, naturalización, paradojas semánticas, composicionalidad.

* I was introduced to Casalegno's argument by Diego Marconi during a course on reference in the fall of 2000, when I was a first-year graduate student. Since the argument perplexed me, I accepted the assignment of writing a paper trying to resist it. I presented my results in talks at the Universities of Bologna and Padova. On 29 May 2001 Casalegno himself gave a talk in Bologna replying to my criticisms. To my eyes, this was a sign of great professionality and philosophical passion: he was taking the work of a young student seriously. Neither my paper nor Casalegno's reply were published then, and, as far as I know, no written trace, except for a brief handout, exists of the latter. One year after Casalegno's untimely death in 2009, having been invited to give a talk at the University of Milano (his university), I decided to rework my paper and present it to honor his memory. I also gave a talk on Casalegno's argument at the University of Torino in November 2014. I publish the paper to demonstrate my great admiration for both the philosophical intelligence and the moral integrity of Casalegno. I thank Ernesto Napoli, Paul Nichols, Marco Santambrogio, and a number of anonymous referees for their comments on earlier versions. 
Is a naturalistic account of reference at all possible? Hilary Putnam's model-theoretic argument to the effect that it is not is well known. However, the weaknesses of his argument have been pointed out many times. ${ }^{1}$ Much less known, partly because it was originally published in Italian (the article where it was advanced was not translated into English until quite recently), is a simpler argument to the same conclusion advanced more than twenty years ago by the late Paolo Casalegno (1995). My aim is to draw attention to this argument and discuss it.

I shall proceed as follows. In Section 1, I shall say something about the idea of naturalizing reference. In Section 2, I shall present Casalegno's argument, which I shall begin to discuss in Section 3. Finally, in Section 4, after a brief but important detour on the compositional structure of natural languages, I shall argue that the argument fails.

\section{The idea of naturalizing reference}

Casalegno's article begins by focusing on a "sort of antinomy regarding the notions of truth and reference" that he takes to be "[ $\mathrm{t}]$ he central problem of the philosophy of language today" $(1995,77)$. On the one hand, "[t] he idea that words correspond to bits of reality and that, in virtue of this correlation between words and things, statements have well-defined truth conditions" is not only "rooted in the pre-theoretical image that we all have of how language works" (ibid.), but informs what Casalegno considers the best research program on the semantics of natural languages, model-theoretic semantics, which "identifies statements' meaning with their truth conditions and systematically deduces these truth conditions from the denotation of simple expressions" $(1995,78)$. On the other hand, he writes, " $\mathrm{t}]$ he traditional explanations of how language can attach to the world are inadequate, and general philosophical considerations seem to indicate that no adequate explanation exists, that nothing can connect linguistic expressions to extra-linguistic entities in the way that we are used to supposing that they are connected, and, hence, that our image of the relation between language and reality is illusory and misleading" $(1995,77)$. With regard to this, Casalegno mentions, in particular, Willard Van Orman Quine's arguments for the inscrutability of reference and subsequent elaborations of them by philosophers such as Donald Davidson and Putnam. All in all, while the notions of truth and reference are both commonsensical and required to theorize about language, their epistemological status is rather dubious: this is precisely the "antinomy" that troubles Casalegno.

Casalegno frankly admits that he has no idea of how to solve the antinomy. On the contrary, his article is devoted to criticising two attempts at solving it by vindicating the notions of truth and reference. The first consists in naturalizing them. The second, which will not concern us, consists in conceiving of them as theoretical notions, whose justification resides in nothing more than the success of the theory that employs them (e.g., modeltheoretic semantics) in explaining the data it purports to explain. ${ }^{2}$

1 For a discussion of Putnam's argument and mention of the relevant literature, see Bianchi 2002.

2 As far as reference is concerned, the latter attempt is hinted at in Davidson's "Reality without reference", an article that clearly inspires Casalegno's. In fact, Casalegno's "antinomy" itself is reminiscent of the "dilemma" outlined in the first two sentences of Davidson's article: "It is difficult to see how a theory of meaning can hope to succeed that does not elucidate, and give a central role to, the concept of reference. On the other hand, there are weighty reasons for supposing that reference cannot be ex- 
Now, even apart from the antinomy, the idea of naturalizing reference is appealing, or so it seems to a number of philosophers (but not to Casalegno, who finds it "perverse" $(1995,79) .^{3}$ In fact, natural languages are an instrument human beings have developed and use to communicate. If human beings are part of the natural world, natural languages should be as well. Thus, it is reasonable to expect that the semantic properties of linguistic expressions be explainable by resorting to the resources used to study that world. Therefore, if, as Casalegno maintains, the notion of reference is needed to characterize those properties, it should be possible to couch it in naturalistic terms. The following passage from Jerry Fodor's Psychosemantics illustrates the point vividly, even though it concerns the aboutness of mental states rather than linguistic reference:

I suppose that sooner or later the physicists will complete the catalogue they've been compiling of the ultimate and irreducible properties of things. When they do, the likes of spin, charm, and charge will perhaps appear upon their list. But aboutness surely won't; intentionality simply doesn't go that deep. It's hard to see, in face of this consideration, how one can be a Realist about intentionality without also being, to some extent or other, a Reductionist. If the semantic and the intentional are real properties of things, it must be in virtue of their identity with (or maybe of their supervenience on?) properties that are themselves neither intentional nor semantic. If aboutness is real, it must be really something else. $(1987,97)$

Moved by such considerations, during the last thirty years some philosophers, Fodor included, set out to offer naturalistic accounts of aboutness. ${ }^{4}$ I think it is fair to say that the results have been much less than satisfying. Each proposal has its own clear shortcomings. Moreover, the strategy generally adopted has been that of focusing on simple representational systems, and it is far from clear that any success in dealing with them may be extended to cover the complexities of natural languages. At any rate, I shall not discuss any of these proposals here, since Casalegno does not. He limits himself to saying that " $\mathrm{i}] \mathrm{t}$ is generally quite easy to pick out the weak points of the individual theories that propose a naturalistic approach to semantics" $(1995,79)$. In fact, Casalegno's aim is much more ambitious: to show in one fell swoop that any such theory is doomed to fail. If he is right, philosophers must simply abandon the idea of naturalizing reference.

Before presenting Casalegno's argument, however, we need to say something more both about the notion at stake, reference, and about the form that any naturalization of it would take.

As we have seen, Casalegno claims that the notion of reference is involved in "our image of the relation between language and reality", and is presupposed by model-theoretic semantics. Unfortunately, in his article he does not devote more time to characterizing it. We may certainly assume that, according to this notion, reference is a relation that linguistic expressions bear to things. But which linguistic expressions, and which things? At one point (pp. 87-88), Casalegno mentions the demonstratives "this" and "that" as expressions

plained or analysed in terms more primitive" $(1977,215)$. However, Casalegno finds Davidson's way out of the dilemma inadequate.

3 In what follows, I shall not say much about the naturalization of truth, since Casalegno's argument does not focus on it. See Field 1972 for some suggestions about how a naturalistic account of truth could be obtained from one of reference, which I shall mention below. See also Bianchi 2016.

4 For an overview, see for example Neander 2006 or Papineau 2006. 
that, relative to a context, refer to an object. ${ }^{5}$ Indeed, they are quite standard examples of referential expressions. However, as we shall see in a moment, Casalegno's argument hinges instead on a compound predicate, taken to be referring to a class of objects, or, alternatively (see below, footnote 8), to some objects. So, it seems that according to Casalegno both singular terms and predicates refer, and so do both syntactically simple expressions and compound expressions. A singular term refers to an object, while a monadic predicate refers to a class of objects, or to some objects (and, more generally, an $n$-place predicate refers to a class of $n$-tuples, or to some $n$-tuples).

Now, some may find Casalegno's way of looking at reference perplexing. It could be claimed that the semantic role of a predicate is not the same as that of a singular term; or that, while a predicate does refer, it does not refer to (the class of) the objects it is true of but to something else (a property that all and only these objects possess, for example); or, again, that the semantic relation a compound expression bears to an object is quite different from the one that a syntactically simple expression bears to it. I, for one, am convinced that the latter point is absolutely crucial for a proper understanding of how language works. I shall come back to this in Section 4. For the moment, just let me make it clear that while all these claims may well be true, by themselves they do nothing to invalidate Casalegno's argument. In fact, just to give an example, both the proper name "Paolo" and the predicate "being a brilliant philosopher" have a relation with Casalegno that depends on the semantic properties of the two expressions. Thus, if semantics is to be naturalized, a naturalistic account must be offered not only of the relation that paradigmatic referential expressions such as proper names or demonstratives bear to their referents but also of the one that simple or compound predicates bear to the objects they are true of. Perhaps, to avoid misunderstanding, one should not call the second relation "reference" (hence, with regard to our example, not say that "being a brilliant philosopher" refers to Casalegno, or to a class of which he is an element), in which case Casalegno's should not be seen as an argument against the naturalization of reference. ${ }^{6}$ But an argument against the naturalization of semantics it would certainly remain. At any rate, for the sake of simplicity, in what follows I shall continue to use the word "reference" as Casalegno does.

Finally, a word about the form that a naturalistic account of reference should take. To succeed, those who aim at it need to find a two-place predicate framed in naturalistically acceptable terms that holds between a linguistic expression and a thing when and only when the former refers to the latter. Actually, what counts as a naturalistically acceptable term is not entirely clear. In the passage quoted above, Fodor mentions "the ultimate and irreducible

5 In fact, in the first passage in which he mentions them, Casalegno takes the speaker rather than the expression to be the first relatum of the relation ("The statement 'This is light' uttered by speaker $S$ in context $\mathrm{C}$ is true if and only if there is an object $\mathrm{X}$ such that, in the context $\mathrm{C}, \mathrm{S}$ refers to $\mathrm{X}$ with the demonstrative 'this' and $\mathrm{X}$ is light"). However, shortly after this he speaks of "the object to which ... the pronoun 'this' refers". Note, moreover, that model-theoretic semantics is not concerned, if not in a very indirect way, with what speakers do.

6 Let me note, however, that Casalegno uses the word "reference" just as Davidson does in the previously mentioned "Reality without reference": "We may take reference to be a relation between proper names and what they name, complex singular terms and what they denote, predicates and the entities of which they are true" $(1977,216)$. In this context, moreover, the use is justified at least in that it complies with that of many of those who attempted to naturalize reference. See, for example, Neander 2006, 374. 
properties of things", of which "sooner or later the physicists will complete the catalogue". To demand that the non-logical expressions compounding the predicate express these properties, however, is preposterous, both because we do not yet know what these properties are and because most notions used in natural sciences are not couched in these terms. A perhaps more reasonable requirement is that in framing the predicate no use be made of notions whose amenability to naturalization is doubtful. This obviously disqualifies intentional notions. If this is so, a naturalistic account of reference should take the following form:

(1) $\forall x \forall y(x$ refers to $y \leftrightarrow x \mathrm{R} y)$,

where $\mathrm{R}$ is expressed, to use Casalegno's words, "in the language of the natural sciences and without recourse to semantic and/or intentional concepts” (1995, 80, translation slightly modified). ${ }^{7}$

What is at stake here is precisely whether any such account has any chance of being true. If Casalegno's argument, which it is now time to examine, works, it does not.

\section{Casalegno's argument}

Casalegno's argument occupies one single paragraph of his article. Here it is, in its entirety:

it seems to me that the best way to convince oneself of the non-naturalisability of the notion of reference remains the following. Suppose that someone proposes to identify reference with a certain natural relation $\mathrm{R}$, and claims that a linguistic expression refers to a certain class $\mathrm{C}$ of objects if and only if it stands in the relation $\mathrm{R}$ to the elements of $\mathrm{C}$. I can easily refute this by adducing the following predicate as a counterexample: "being an object that does not stand in the relation $\mathrm{R}$ to this expression". Let us call this predicate $\mathrm{P}$. What does $\mathrm{P}$ refer to? Obviously to all and only those objects that do not stand in the relation $\mathrm{R}$ to $\mathrm{P}$. Therefore it is not the case that $\mathrm{P}$ refers to objects that stand to it in the relation $\mathrm{R}$. Therefore it is not the case that a linguistic expression refers to a certain class of objects if and only if it stands to them in the relation R. How could a naturaliser reply? To resist my argument, he would have to reply either that, despite appearances, the predicate $\mathrm{P}$ does indeed refer to objects that stand in the relation $\mathrm{R}$ to it, or that the expression is senseless and without reference. [But it seems to me that neither claim is reasonable. To say that $\mathrm{P}$ refers to the objects that stand in the relation $\mathrm{R}$ to it is to say something gratuitous, in contrast to intuition and in conflict with the assumption that the reference of complex expressions is obtained compositionally from that of simple expressions. It would be no less preposterous, in my opinion, to claim that the predicate $\mathrm{P}$ is without reference. (Passage present in the original article but strangely omitted in the English translation. Translation mine.)] Certainly, it is not a paradoxical expression unlike a predicate like "being an object to which this expression does not refer". We should bear in mind that, ex hypothesi, $\mathrm{R}$ is a well-defined relation expressed in the language of the natural sciences and without recourse to semantic and/or intentional concepts. But

7 As a matter of fact, something stronger than (1) is required, since (1) states only a de facto co-extensionality, while the naturalizer aims at identity (in which case at least co-intensionality is needed) or supervenience (see the quotation from Fodor). However, we may leave modal issues aside, since in his argument Casalegno aims to show that not even (1) is true. Let me add here that it is important to keep in mind that in (1) " $x \mathrm{R} y$ " is a signpost for an open sentence that will certainly be rather complex, since reference is not, to use Fodor's jargon, one of the "ultimate and irreducible" relations between things. If this is so, the sentence will contain many connectives and other operators. In particular, it might have a disjunctive form (see below). 
if that is the case, the predicate "being an object that does not stand in the relation $\mathrm{R}$ to this expression" seems to be perfectly understandable and usable without any problems. With a bit of luck, we might even be able to pick out the objects that do not stand in the relation $\mathrm{R}$ with the expression and thus to specify which are the objects that the expression refers to. In conclusion: the naturaliser will be unable to formulate any well-founded objection to my counterexample. (1995, 80 , translation slightly modified)

The only comment by Casalegno is the following, after which he moves on to a discussion of the attempt at vindicating the notions of truth and reference by conceiving of them as theoretical notions, an argument which occupies the remaining, largest, part of his article:

I am quite aware that this reasoning is perhaps rather too ethereal to be taken seriously by the naturalisers, who are on the whole people whose imagination is struck only by what is concrete and bodily. But, as I have said, it is the best line of argument that I know of. And, at bottom, I think that it reflects a sound intuition, according to which it is easy to refer to something, enormously easier than to guarantee that any "natural" relation whatsoever holds. (1995, 80-81)

The structure of the argument is in fact quite simple. Its only premise is that the predicate "being an object that does not stand in the relation $\mathrm{R}$ to this expression" refers to all and only those objects that do not stand in the relation $\mathrm{R}$ to it, where $\mathrm{R}$ is whatever relation is supposed to naturalize reference. Following Casalegno, we may call the predicate "P". It is important to keep in mind, however, that, while $\mathrm{P}$ is a predicate, "P" is not: it is a proper name of a predicate. For this reason, I shall use a capital "P" in the text, to comply with Casalegno's choice, but a lower-case " $p$ " in formalizations, where it plays the role of an individual constant. The premise of Casalegno's argument can then be represented as

(2) $\forall y(p$ refers to $y \leftrightarrow-(p \mathrm{R} y))$,

from which

(3) $\exists y(p$ refers to $y \leftrightarrow-(p \mathrm{R} y))$

obviously follows. (3) implies

(4) $\exists y-(p$ refers to $y \leftrightarrow p \mathrm{R} y)$,

from which, by existential generalization, we obtain

(5) $\exists x \exists y-(x$ refers to $y \leftrightarrow x \mathrm{R} y)$,

that is,

(6) $\exists x \neg \forall y$ ( $x$ refers to $y \leftrightarrow x \mathrm{R} y$ ),

that is,

(7) $-\forall x \forall y$ ( $x$ refers to $y \leftrightarrow x \mathrm{R} y$ ).

Now, (7) is the negation of (1), the alleged naturalistic account of reference. ${ }^{8}$ Hence, since on the face of it the argument does not depend on the choice of R, it seems that we are forced to conclude that any attempt at naturalizing reference is doomed to fail.

8 Actually, Casalegno's formulation of the naturalizing hypothesis is a bit different, since mention of a class is made in it ("a linguistic expression refers to a certain class $\mathrm{C}$ of objects if and only if it stands in 


\section{P: a dangerous predicate}

Casalegno's argument is certainly valid. If (2) is true, (1), no matter what the relation that is supposed to naturalize reference is, is false. ${ }^{9}$ To resist its conclusion, then, one needs to claim that (2) is not true, namely that it is not the case that the predicate "being an object that does not stand in the relation $\mathrm{R}$ to this expression" refers to all and only those objects that do not stand in the relation $\mathrm{R}$ to it. ${ }^{10} \mathrm{In}$ fact, in the second part of the passage quoted, Casalegno argues against what seem to be the only two options for doing this.

On the face of it, the claim that "being an object that does not stand in the relation $\mathrm{R}$ to this expression" refers to all and only those objects that do not stand in the relation R to it is indeed quite reasonable. Just like the claim that "being a brilliant philosopher" refers to all and only those philosophers who are brilliant, it appears to be justified by the principle of compositionality for English - a principle, moreover, on which model-theoretic semantics crucially rests. In particular, I think that Casalegno is right in dismissing the contrary claim that $\mathrm{P}$ refers to all and only those objects that stand in the relation $\mathrm{R}$ to it, which seems to be implied by (1), the alleged naturalistic account of reference. As Casalegno sensibly writes, "to say that $\mathrm{P}$ refers to the objects that stand in the relation $\mathrm{R}$ to it is to say something gratuitous, in contrast to intuition and in conflict with the assumption that the reference of complex expressions is obtained compositionally from that of simple expressions". Actually, it would be like saying that "being a brilliant philosopher" refers to all and

the relation $\mathrm{R}$ to the elements of C"). This is quite strange, both because it is odd to take all linguistic referring expressions to refer to classes and because, when dealing with $P$, Casalegno himself writes that it refers "to all and only those objects that do not stand in the relation R to P", rather than to the class of them. Regarding predicates, however, the claim that they refer to classes is certainly less perplexing. Indeed, an anonymous referee wrote: "while I can make sense of the claim that a predicate refers to a class of objects or that it refers to a property .... I find it harder to make sense of the claim that a predicate refers to some objects". To those having the same feeling, I suggest reading "refers" in the naturalizing hypothesis as meaning is true of, or is satisfied by, at least when predicates are concerned, and viewing Casalegno's argument as dealing with this relation. But if one wanted to stick to reference and to the idea that predicates refer to classes, it would be easy to reformulate the argument. One way to do this is simply to take $y$ in the representation of the naturalizing hypothesis as ranging over classes, and $\mathrm{P}$ as "being a class that does not stand in the relation $\mathrm{R}$ to this expression". Another way, perhaps more faithful to Casalegno's intentions, is instead to formalize the naturalizing hypothesis as " $\forall x \forall y$ ( $x$ refers to $y \leftrightarrow \forall z((z \in y) \leftrightarrow(x \mathrm{R} z)))$ ", again with $y$ ranging over classes, and with $\mathrm{P}$ as in the text.

9 Let me add, by the way, that another way to use (2) to refute (1) is in a reductio ad absurdum of it. Indeed, if we assume (1), from (2), by substitution of co-extensional expressions, we may obtain " $\forall y$ $(p \mathrm{R} y \leftrightarrow \neg(p \mathrm{R} y))$ ", which is a contradiction. Hence, (1) is false, no matter what relation R is.

10 An alleged alternative has been sometimes suggested to me, namely that of claiming that $\mathrm{P}$ has an empty extension (like, for example, "being non self-identical"). Now, the naturalizer can certainly make a similar claim, and even provide apparently good reasons in favor of it. It is important to realize, however, that this, far from helping in resisting Casalegno's argument, would allow him to bring home his conclusion. In conjunction with the principle of compositionality, in fact, the claim that $\mathrm{P}$ has an empty extension implies (2), from which, as we have just seen, Casalegno's conclusion follows. As I shall argue below, then, rather than claiming that $\mathrm{P}$ has an empty extension the naturalizer would do better to argue that, under certain conditions, $\mathrm{P}$ has no extension at all, namely that it is not, in Casalegno's sense, a referring expression. This is so if $\mathrm{P}$ is paradoxical. See below. 
only those who are not brilliant philosophers, and so, for example, to Donald Trump rather than to Casalegno. Not an interesting option.

Much more promising, in my opinion, is the second option that Casalegno briefly discusses. According to this, $\mathrm{P}$ is paradoxical. If it were so, it would be, as Casalegno writes, "senseless and without reference", hence (2) would not be true and Casalegno's argument would be rendered ineffective.

Now, $\mathrm{P}$ is a predicate involving self-reference, and this cannot but render it suspect, given that we all know how self-reference sometimes leads to paradox. However, we all also know that in many other cases self-reference is innocuous, and that a general ban on self-reference is neither necessary nor sufficient for avoiding, and so not a good strategy for dealing with, semantic paradoxes. ${ }^{11}$ What's more, there are certainly many predicates having the same self-referential form as $\mathrm{P}$ that are not paradoxical at all. Take "being an object this expression is not identical to", for example. In this case, we have absolutely no reason not to accept the analogous claim of (2), i.e. that "being an object this expression is not identical to" refers to all and only those objects it is not identical to. Hence, we need to admit that it is not the case that $\mathrm{P}$ is paradoxical only by virtue of its self-referential form. However, we also know that there are some other predicates having the same form as $\mathrm{P}$ that are indeed paradoxical. Casalegno himself mentions one, which is "being an object this expression does not refer to". With regard to the latter, obviously we cannot accept that it refers to all and only those objects it does not refer to.

Let me recap. We have seen that the only serious way to resist Casalegno's conclusion is to claim that $\mathrm{P}$ is paradoxical, and that, while it is not the case that $\mathrm{P}$ is paradoxical only by virtue of its self-referential form, there are certain predicates having the same form as it that are paradoxical. This means that, as far as paradoxicality is concerned, much depends on what $\mathrm{R}$, the relation mentioned within $\mathrm{P}$, is (for example, reference would engender a paradox, while identity would not).

Now, the only reason that Casalegno offers for claiming that $\mathrm{P}$ is not paradoxical, and thus that the premise of his argument can only be true, is that "ex hypothesi, $\mathrm{R}$ is a well-defined relation expressed in the language of the natural sciences and without recourse to semantic and/or intentional concepts". (By the way, let me note that this is the only point in Casalegno's reasoning where use is made of the hypothesis that $\mathrm{R}$ is a natural relation. If it were not for this, one might legitimately conclude that no account whatsoever of reference is possible.) Unfortunately, this seems to beg the question, since it amounts to saying that " $R$ ", whatever natural relation $R$ is, is not coextensive with "reference" (if it were, $P$ should turn out to be paradoxical, since "being an object this expression does not refer to" is). ${ }^{12}$ However, it is certainly true that the natural relations that first come to mind

11 With regard to this, see for example Kripke 1975, 694 n. 9 and 698 n. 13; Field 2008, 118.

${ }^{12}$ Let me note here that, apart from being question-begging, Casalegno's assumption that the language of natural sciences cannot give rise to paradoxes is anyway questionable, as an anonymous referee suggested to me by giving an ingenious example. Define, as usual in zoology, a cannibalistic species as a biological species whose individuals consume as food individuals of the same species, and consider a hypothetical species (call it "Tonsor pseudoautophagus") whose members consume as food individuals of any species that is not cannibalistic and do not consume as food individuals of any species that is cannibalistic. It follows from this that Tonsor pseudoautophagus is a cannibalistic species if and only if it is not a cannibalistic species. Indeed, this is nothing more than a variant of the barber paradox. Should 
(for an example dear to many naturalists, think of causal relations) are such that the resulting predicates with the form of $\mathrm{P}$ are not problematic. So, it seems to me that the best way of understanding Casalegno's last point is as a challenge: can we make sense of a relation that is natural (in the sense explained above) but that renders the resulting predicate P mentioning it paradoxical? In the next Section, I shall try to argue that we can, and thus that the naturalizer can meet Casalegno's challenge.

\section{An interesting natural relation}

In Section 1, I happened to mention that with regard to reference there seem to be significant differences between simple and compound expressions. In fact, while compound expressions refer because simple expressions do, it is not generally the case that the latter refer because the former do. ${ }^{13}$ More precisely, while the reference of compound expressions is generally a function of the reference of the simple expressions that compound them, the reference of simple expressions is not a function of the reference of any other expression. ${ }^{14}$ This is a basic fact about languages: they have a compositional structure. Indeed, this is mentioned by Casalegno himself in two different passages of his article, to characterize modeltheoretic semantics (which "identifies statements' meaning with their truth conditions and systematically deduces these truth conditions from the denotation of simple expressions") and to defend the premise of his argument (which follows from "the assumption that the reference of complex expressions is obtained compositionally from that of simple expressions").

If we look at this basic fact about languages in a metaphysical light, an interesting conclusion is forced upon us, or so it seems to me: reference is constituted by two distinct relations. The first is not linguistically mediated and holds between simple expressions and the objects they refer to, whereas the second is linguistically mediated and holds between compound expressions and the objects they refer to. The latter (let us call it "reference ${ }_{2}$ ") is parasitic on the former ("reference,"), which is, in some sense perhaps difficult to specify, primitive. ${ }^{15}$ Therefore, we may state the following:

we conclude that there is no place in the language of the natural sciences for the expression "cannibalistic species"? Of course not, since the notion of cannibalistic species is commonly employed in zoology. Simply, we have to say that "Tonsor pseudoautophagus" is without reference.

${ }^{13}$ I write "generally" because there may be syntactically simple expressions that are not semantically (Bertrand Russell would have said "logically") simple, in that they abbreviate compound expressions. See footnote 15 below.

${ }^{14}$ Here, instead, I write "generally" because there are syntactically compound expressions that are not semantically compound (e.g., "the Holy Roman Empire"). For the sake of simplicity, I shall ignore this in what follows. I think that all I am going to say may be adjusted to accommodate it.

15 This distinction is at least as old as Russell. With different terminology and in relation to a quite simple language, it is stressed by Hartry Field in the following passage (whose continuation will be mentioned in a moment): "It is convenient to introduce the expression 'primitively denotes' as follows: every name primitively denotes what it denotes; every predicate and every function symbol primitively denotes what it applies to or is fulfilled by; and no complex expression primitively denotes anything" $(1972,6)$. In another context, Michael Devitt writes: "There must be some primitives because not all words can have their meanings explained in terms of the meanings of other terms; not all words can 
(8) $\forall x \forall y$ ( $x$ refers to $y \leftrightarrow\left(\left(x\right.\right.$ is simple $\wedge x$ refers $_{1}$ to $\left.y\right) \vee\left(x\right.$ is compound $\wedge x$ refers $_{2}$ to $y)))$.

If this is so, a two-stage naturalization of reference suggests itself. What should be offered is a naturalistic account of reference ${ }_{1}$, the relation holding between simple expressions and the objects they refer to, and one of reference ${ }_{2}$, the relation holding between compound expressions and the objects they refer to. By putting the two together, the aim of offering a naturalistic account of reference would finally be achieved.

The first step would then be that of finding a two-place predicate framed in naturalistically acceptable terms holding between a simple linguistic expression and a thing when and only when the former refers 1 to the latter, because, as should be clear, a naturalistic account of reference ${ }_{1}$ should take the following form:

(9) $\forall x \forall y\left(x\right.$ refers $_{1}$ to $\left.y \leftrightarrow x \mathrm{R}_{1} y\right)$,

where $\mathrm{R}_{1}$ is expressed, to use once again Casalegno's words, "in the language of the natural sciences and without recourse to semantic and/or intentional concepts". Obviously, we do not know yet whether any such two-place predicate exists, but it is important to notice that against something taking the form of (9) no argument like Casalegno's is viable.

To see this, consider the predicate "being an object that does not stand in the relation $\mathrm{R}_{1}$ to this expression" (call it " $\mathrm{P}_{1}$ ”), and try to formulate a premise similar to that of Casalegno's argument. We have no reason whatsoever to accept that "being an object that does not stand in the relation $\mathrm{R}_{1}$ to this expression" refers ${ }_{1}$ to all and only those objects that do not stand in the relation $\mathrm{R}_{1}$ to it, namely,

(10) $\forall y\left(p_{1}\right.$ refers $_{1}$ to $\left.y \leftrightarrow \neg\left(p_{1} \mathrm{R}_{1} y\right)\right)$,

since "being an object that does not stand in the relation $\mathrm{R}_{1}$ to this expression" is a compound expression, while reference ${ }_{1}$ is a relation that only simple expressions bear to the objects they refer to. On the contrary, that "being an object that does not stand in the relation $\mathrm{R}_{1}$ to this expression" refers to all and only those objects that do not stand in the relation $\mathrm{R}_{1}$ to it, namely,

(11) $\forall y\left(p_{1}\right.$ refers to $\left.y \leftrightarrow \neg\left(p_{1} \mathrm{R}_{1} y\right)\right)$,

follows from "the assumption that the reference of complex expressions is obtained compositionally from that of simple expressions", hence it is reasonably true. However, it cannot be used to refute the alleged naturalistic account of reference ${ }_{1}$, since from it only

(12) $\neg \forall x \forall y\left(x\right.$ refers to $\left.y \leftrightarrow x \mathrm{R}_{1} y\right)$

pass the semantic/referential buck" $(2011,200 \mathrm{n} .8)$. This said, it must be admitted that characterizing the class of the primitives is not at all easy, since, as I wrote in footnote 13, there may be syntactically simple expressions that are not semantically simple (i.e., primitive in Devitt's sense), in that they abbreviate compound expressions. It is a vexata quaestio in both philosophy of language and philosophy of mind how many of them there are (if any). Is "animal" one of them? "Doorknob"? "Bachelor"? Luckily, I do not need to provide answers to such questions here. For the purposes of this paper, in fact, what is important to realize is only that $\mathrm{P}$ is a compound expression both from a syntactic and a semantic point of view, and that any abbreviation of it would still count as a compound expression from a semantic point of view: its semantic properties would be obtained compositionally from those of the simple expressions that occur in P. 
may be deduced, and (12) is not the negation of (9), nor of anything else that has been stated up to now.

So far, so good. But what about reference ${ }_{2}$, the relation holding between compound expressions and the objects they refer to? Here, again, a naturalistic account of it should take the form of

(13) $\forall x \forall y\left(x\right.$ refers $_{2}$ to $\left.y \leftrightarrow x \mathrm{R}_{2} y\right)$,

with the usual constraints on $\mathrm{R}_{2}$. However, we know something interesting about reference $_{2}$ which may be useful for giving substance, so to speak, to $\mathrm{R}_{2}$. In fact, we know that reference $_{2}$ is somehow parasitic on reference ${ }_{1}$. More precisely, we know that it is a basic fact about languages that they have a compositional structure: the reference of compound expressions is obtained compositionally from that of simple expressions. Moreover, we know how this is obtained: the syntactic structure of a compound expression determines which function needs to be computed to obtain its reference from that of the simple expressions that occur in it. Thus, we may state something like the following:

(14) $\forall x \forall y$ ( $x$ refers $_{2}$ to $y \leftrightarrow y$ is the value of the function associated to the syntactic structure of $x$ when it takes as arguments the objects (or classes) the simple expressions occurring in $x$ refer $_{1}$ to). ${ }^{16}$

Now, let us ask: Is (14) something the naturalizer may appeal to in order to provide a naturalistic account of reference 2 ? On the face of it, on the right side of the biconditional use is made of two semantic concepts (those expressed by "is associated to" and "refer ${ }_{1}$ to"), and this would seem to disqualify (14). However, naturalizers should not be scared of "refer ${ }_{1}$ to", if they have succeeded in the first stage of their naturalization. But what about "is associated to"? Here, some perhaps unexpected help comes from model-theoretic semantics, which, among other things, may be seen as an attempt at eliminating it by providing a recursive definition of the set of referential expressions, accompanied by a specification of how each of the rules listed in the recursive clause contributes to determining the function that needs to be computed to obtain the reference of the compound expression. ${ }^{17}$ The result would be something that does not use any semantic concept except that of reference ${ }_{1}{ }^{18}$ Thus, if model-theoretic semanticists succeed in this, and naturalizers succeed in finding a

${ }^{16}$ Here, to assume that the reference of a predicate is a class simplifies the exposition. Nothing substantial, however, hinges on this. In what follows, I shall omit the parenthetical "or classes" throughout.

${ }^{17}$ Let me note here that I only keep referring to model-theoretic semantics because this was Casalegno's choice. Obviously, a truth-conditional approach à la Davidson could serve the same purpose.

18 This point is stressed by Field in the continuation of the passage mentioned in footnote 15: "In this terminology, what T1 [Field's version of a Tarskian truth definition for the simple language he is considering] does is to explain truth in terms of primitive denotation. Similarly we can explain denotation for arbitrary closed singular terms ( $\operatorname{such}$ as $\left.\left(f_{1}\left(c_{1}\right)\right)^{\prime}\right)$ in terms of primitive denotation, i.e., in terms of the semantic features of the names and function symbols from which the complex singular term is composed .... We see then that Tarski*s semantics [Field's version of Tarski's semantics] explains the semantic properties of complex expressions (e.g., truth value for sentences, denotation for complex singular terms) in terms of semantic properties of their primitive components" $(1972,6)$. For a discussion of Field's version of Tarski's semantics, see Sher 1999. Of course, the richer language is, the more complicated things become. However, that the task of model-theoretic semantics is precisely to offer this kind of theory for natural languages is hinted at by Casalegno himself when he writes that model-theoretic se- 
naturalistic account of the relation that simple expressions bear to the objects they refer to, then, contrary to appearance, (14) is formulated in terms that are naturalistically acceptable. If this is so, whilst waiting for developments in model-theoretic semantics, we may at least provisionally accept that

(15) $\forall x \forall y$ ( $x$ refers to $_{2}$ to $y \leftrightarrow y$ is the value of the function associated to the syntactic structure of $x$ when it takes as arguments the objects that stand in the relation $\mathrm{R}_{1}$ to the simple expressions occurring in $x$ )

is a naturalistic account of reference ${ }_{2}$ if $R_{1}$ is the relation that naturalizes reference ${ }_{1}$.

By putting together (9) and (15), we finally obtain the form that a naturalistic account of reference attentive to the compositional structure of languages would take:

(16) $\forall x \forall y$ ( $x$ refers to $y \leftrightarrow\left(\left(x\right.\right.$ is simple $\left.\wedge x \mathrm{R}_{1} y\right) \vee(x$ is compound $\wedge y$ is the value of the function associated to the syntactic structure of $x$ when it takes as arguments the objects that stand in the relation $\mathrm{R}_{1}$ to the simple expressions occurring in $x))$ ).

Now, the important question. Does Casalegno's argument work against a naturalistic account taking this form? To answer, we first need to build a predicate like $\mathrm{P}$ from the negation of the open formula on the right side of the biconditional in (16). Here it is: "being an object $y$ such that it is not the case that ((this expression is simple and $y$ stands in the relation $\mathrm{R}_{1}$ to it) or (this expression is compound and $y$ is the value of the function associated to the syntactic structure of this expression when it takes as arguments the objects that stand in the relation $\mathrm{R}_{1}$ to the simple expressions occurring in this expression))". Its complexity does make it quite difficult to process, but a moment of reflection shows that because of its being compound the predicate is equivalent to the simpler "being an object that is not the value of the function associated to the syntactic structure of this expression when it takes as arguments the objects that stand in the relation $R_{1}$ to the simple expressions occurring in this expression". Let us call this predicate " $\mathrm{P}_{2}$ ". Now, the truth of the premise of Casalegno's argument, we know, depends on $\mathrm{P}_{2}$ not being paradoxical. But the fact is precisely that $\mathrm{P}_{2}$ is paradoxical, if $\mathrm{R}_{1}$ naturalizes reference. ${ }_{1}$. Indeed, under this hypothesis $\mathrm{P}_{2}$ is equivalent to the predicate "being an object that is not the value of the function associated to the syntactic structure of this expression when it takes as arguments the objects the simple expressions occurring in this expression refer ${ }_{1}$ to", which we are forced to consider - to use Casalegno's words again - "senseless and without reference", in order not to say that it refers to something if and only if it does not refer to it. Therefore, we may conclude that Casalegno's argument is ineffective against a naturalistic account taking the form of (16).

Before addressing an objection to this line of reasoning, it may be useful to briefly go back over the path that led us here. As we have seen, Casalegno offers an argument to the effect that no naturalistic account of reference is possible. His argument crucially rests on a premise concerning a certain predicate mentioning the relation that purportedly naturalizes reference. Since the conclusion clearly follows from that premise, the

mantics "identifies statements' meaning with their truth conditions and systematically deduces these truth conditions from the denotation of simple expressions". 
only way to resist the argument is to claim that the premise is not true. As Casalegno himself notes, the premise would indeed not be true if the predicate that it concerns were paradoxical. Now, the predicate involves some self-reference, and this renders it at least suspect. We saw, however, that if it is paradoxical, it is not so by virtue of its selfreferential form alone: much depends on the relation mentioned within it. Casalegno claims that, since "ex hypothesi" the latter is "a well-defined relation expressed in the language of the natural sciences and without recourse to semantic and/or intentional concepts", the resulting predicate cannot be paradoxical. I objected that this begs the question, since it amounts to assuming what should be demonstrated, that is that reference is not a natural relation - in fact, a predicate with the same self-referential form mentioning reference is paradoxical, as Casalegno is ready to admit. So, I ended the preceding Section by claiming that Casalegno's argument is not conclusive. It can at best be seen as a (serious) challenge to the naturalizers: can they make sense of a relation that is natural but that renders the resulting self-referential predicate mentioning it paradoxical? In this Section, I took pains to show that they can. Indeed, I argued that there is a family of natural relations having a certain structure (isomorphic, so to speak, to that of reference, which is compositional) that are such that the self-referential predicates mentioning them might turn out to be paradoxical. More precisely, the latter will be paradoxical if the relation defining the relation mentioned in them naturalizes the relation that the simple expressions of language bear to the objects they refer to. ${ }^{19}$ Hence, provided there is a relation naturalizing reference for simple expressions, there is at least one natural relation that is such that the self-referential predicate mentioning it is paradoxical: the one defined by means of the former and taking account of compositionality. Hence, Casalegno's challenge is met. Moreover, against attempts at naturalizing reference appealing to natural relations with a structure such as the one described, Casalegno's argument is ineffective, because we cannot know a priori that its premise is true (though it may certainly turn out to be true, if the natural relation by which the natural relation appealed to is defined turns out not to be coextensive with reference for simple expressions; but in this case, Casalegno's argument would be superfluous, since that particular naturalistic account would already be disproved).

Now, let me briefly discuss an objection that might be raised, and has actually been raised (by Diego Marconi and Casalegno himself a long time ago and by an anonymous referee more recently) against my reasoning. I have argued that, assuming that the relation $\mathrm{R}_{1}$ mentioned within it naturalizes reference ${ }_{1}, \mathrm{P}_{2}$ is paradoxical. But had $\mathrm{I}$ the right to make that assumption? Isn't this way of arguing begging the question in exactly the same way as Casalegno's (see above)? To meet Casalegno's challenge, shouldn't one make sense of a relation that is natural but that renders the resulting self-referential predicate mentioning it paradoxical quite independently of any connection it may have with reference

19 That an expression may prove to be paradoxical only a posteriori is not at all surprising. On the contrary, some decades ago Kripke was already arguing convincingly that "many, probably most, of our ordinary assertions about truth and falsity are liable, if the empirical facts are extremely unfavorable, to exhibit paradoxical features" $(1975,691)$. Indeed, what Kripke said about his example ("Most (i.e., a majority) of Nixon's assertions about Watergate are false") may be repeated for $\mathrm{P}_{2}$ : "no syntactic or semantic feature of [it] guarantees that it is unparadoxical" $(1975,692)$. I thank an anonymous referee for drawing my attention to this. 
or other semantic or intentional properties or relations? Even worse, doesn't the fact that $\mathrm{P}_{2}$ is paradoxical if $\mathrm{R}_{1}$ naturalizes reference ${ }_{1}$ refute the hypothesis itself that $\mathrm{R}_{1}$ naturalizes reference $_{1}$ ? And again, how could a natural relation engender paradoxes? Finally, if the assumption above were legitimate, wouldn't the assumption that $\mathrm{R}$ naturalizes reference be equally legitimate? If so, Casalegno's challenge could be met much more easily, without the need of any long detour through the compositional structure of languages.

Not so, I claim. Assuming that $\mathrm{R}$ naturalizes reference in order to meet Casalegno's challenge would in fact be as question-begging as Casalegno's assuming that natural relations cannot engender paradoxes (i.e., as we have seen, that reference is not a natural relation) in order to defend a premise needed to argue that any attempt at naturalizing reference is doomed to fail. The result would be something like a dialectical deadlock: Casalegno would not be able to convince the naturalizer, but the naturalizer would not be any abler to convince Casalegno. On the contrary, it seems to me that our detour through the compositional structure of languages has provided us with positive reasons for believing that there may be natural relations that are such that the resulting self-referential predicates mentioning them are paradoxical, and so, that the premise of Casalegno's argument, for some appropriate choice of R, may fail to be true. In fact, we now know how naturalizers may hope to find one such relation: they should search for a relation that naturalizes reference for simple expressions, and take on board the account that model-theoretic semanticists offer of how the reference of compound expressions is obtained from that of simple expressions. To claim that the fact that the resulting predicate $P_{2}$ is paradoxical if $R_{1}$ naturalizes reference for simple expressions shows that no relation may naturalize reference for simple expressions is preposterous, or so it seems to me. If it showed this, it would ipso facto show that reference for simple expressions is somehow problematic, in that it engenders semantic paradoxes. But we all know that this is not so. Reference for simple expressions (our reference $_{1}$ ) is a quite respectable relation, totally defined, in the sense that for any pair of entities it holds between them or it does not. Because of this, it is apt to be naturalized (which, obviously, does not mean that a naturalistic account of it is easy to find, or even that it exists). ${ }^{20}$ What is responsible for engendering semantic paradoxes is on the contrary something not yet well understood in the logico-compositional apparatus of languages. ${ }^{21} \mathrm{But}$ in

${ }^{20}$ An anonymous referee wrote that my "argument for the paradoxicality of Casalegno's self-referential predicate rests on an unwarranted premise", namely that "there is a relation that naturalizes reference for simple expressions". He or she criticized me for failing "to provide adequate support" for this "central assumption", which "cannot be taken for granted", (also) because of "Chomsky's arguments" against it. On the latter, see Chomsky 1992, 36-45; 1993, 22-28. Now, if those arguments work, reference is indeed not naturalizable, but this is completely beside the point. In fact, here I am considering a different argument, proposed by Casalegno, against the naturalization of reference, which obviously cannot rest on Chomsky's. What is important to notice is that, in order to display the failure in this argument, I certainly do not need to "provide adequate support" for the "central assumption". On the contrary, it is sufficient to point out that Casalegno cannot assume that the assumption is false without circularity. If this is so, he cannot exclude that $\mathrm{P}_{2}$ is paradoxical, and therefore cannot conclude that any attempt at naturalizing reference is doomed to fail.

21 With regard to this, it is worth noting that if we impoverish a language such as English of part of its logico-compositional apparatus but keep all its simple referring expressions, we may get a language free of paradoxes. 
a naturalist account of reference attentive to compositionality (one based on something like (16) above) the part dealing with this apparatus can simply be borrowed from modeltheoretic semantics! If paradoxes are to be avoided, then, something needs to be fixed there. What is certain, however, is that the fact that $P_{2}$ is paradoxical if $R_{1}$ naturalizes reference for simple expressions may in no way be used to argue that no naturalistic account of reference for simple expressions, and a fortiori no naturalistic account for reference tout court, is possible.

With this, my examination of Casalegno's argument comes to an end. Let me just conclude by stressing that, while I have tried to show that it ultimately fails, I believe that the argument teaches us something important, by directing our attention to the compositional structure of languages. Indeed, what is crucial to my rejection of Casalegno's conclusion is, as we have seen, a clear distinction between simple and compound expressions, and between the different relations they bear to the things they refer to (as I suggested above, it may perhaps be useful to this end to stop calling both of them "reference"). If I am right, whether any attempt at naturalizing reference that takes care of these distinctions will succeed remains an open empirical question, notwithstanding Casalegno's ingenious argument. A hard task, obviously, remains: finding a relation that naturalizes reference for simple expressions. But this is another story...

\section{REFERENCES}

Bianchi, Andrea. 2002. Naturalizing Semantics and Putnam's Model-Theoretic Argument. Episteme NS 22, no. 1: 1-19.

Bianchi, Andrea. 2016. Truth: Some Preliminary Considerations. In The Importance of Being Called Ernesto: Reference, Truth, and Logical Form, edited by Andrea Bianchi, Vittorio Morato, and Giuseppe Spolaore, 195-213. Padova: Padova University Press.

Casalegno, Paolo. 1995. Tre osservazioni su verità e riferimento. Iride 16: 615-27. Translated in English as "Three Remarks on Truth and Reference." In Paolo Casalegno, Truth, Meaning and the Analysis of Natural Language, edited by Pasquale Frascolla, Diego Marconi, and Elisa Paganini, 77-89. Newcastle: Cambridge Scholar Publishing, 2013 (page numbers given relate to this volume).

Chomsky, Noam. 1992. Explaining Language Use. Philosophical Topics 20, no. 1: 205-31. Reprinted in Noam Chomsky, New Horizons in the Study of Language and Mind, 19-45. Cambridge: Cambridge University Press, 2000 (page numbers given relate to this volume).

Chomsky, Noam. 1993. Language and Thought. Wakefield: Moyer Bell.

Davidson, Donald. 1977. Reality Without Reference. Dialectica 31, no. 3-4: 247-58. Reprinted in Donald Davidson, Inquiries into Truth and Interpretation, 215-25. Oxford: Clarendon Press, Second edition 2001 (page numbers given relate to this volume).

Devitt, Michael. 2011. Deference and the Use Theory. ProtoSociology 27: 196-211.

Field, Hartry. 1972. Tarski's Theory of Truth. Journal of Philosophy 69, no. 13: 347-75. Reprinted with a postscript in Hartry Field, Truth and the Absence of Fact, 3-29. Oxford: Clarendon Press, 2001 (page numbers given relate to this volume).

Field, Hartry. 2008. Saving Truth from Paradox. Oxford: Oxford University Press.

Fodor, Jerry A. 1987. Psychosemantics: The Problem of Meaning in the Philosophy of Mind. Cambridge, MA: The MIT Press. 
Kripke, Saul. 1975. Outline of a Theory of Truth. Journal of Philosophy 72, no. 19: 690-716.

Neander, Karen. 2006. Naturalistic Theories of Reference. In The Blackwell Guide to the Philosophy of Language, edited by Michael Devitt and Richard Hanley, 374-91. Oxford: Blackwell.

Papineau, David. 2006. Naturalist Theories of Meaning. In The Oxford Handbook of Philosophy of Language, edited by Ernest Lepore and Barry C. Smith, 175-88. Oxford: Clarendon Press.

Sher, Gila. 1999. What is Tarski's Theory of Truth? Topoi 18: 149-66.

ANdRea BiAnchi is an associate professor of philosophy of language at the University of Parma. He has published various articles on reference and related topics, and edited On Reference (OUP 2015).

Address: Università degli Studi di Parma, Dipartimento di Discipline Umanistiche, Sociali e delle Imprese Culturali, Unità di Filosofia, via D’Azeglio 85, 43125 Parma, Italia. E-mail: an.bianchi@libero.it 